Research Article

\title{
Optimization of Layout and Pipe Sizes for Irrigation Pipe Distribution Network Using Steiner Point Concept
}

\author{
Preeti Walmik Gajghate ${ }^{(D)},{ }^{1}$ Ashwini Mirajkar ${ }^{(D},{ }^{1}$ Uzma Shaikh $\left(\mathbb{D},{ }^{1}\right.$ \\ Neeraj Dhanraj Bokde ${ }^{(D},{ }^{2}$ and Zaher Mundher Yaseen ${ }^{3}{ }^{3}$ \\ ${ }^{1}$ Visvesvaraya National Institute of Technology, Nagpur 440010, India \\ ${ }^{2}$ Department of Mechanical and Production Engineering-Renewable Energy and Thermodynamics, Aarhus University, \\ Aarhus 8000, Denmark \\ ${ }^{3}$ Faculty of Civil Engineering, Ton Duc Thang University, Ho Chi Minh City, Vietnam
}

Correspondence should be addressed to Zaher Mundher Yaseen; yaseen@tdtu.edu.vn

Received 5 December 2020; Revised 16 February 2021; Accepted 20 February 2021; Published 27 February 2021

Academic Editor: Noorbakhsh Amiri Golilarz

Copyright ( 92021 Preeti Walmik Gajghate et al. This is an open access article distributed under the Creative Commons Attribution License, which permits unrestricted use, distribution, and reproduction in any medium, provided the original work is properly cited.

\begin{abstract}
In tropical countries like India, irrigation is necessary to grow crops in the nonmonsoon period. The conventional methodology for conveying irrigation water from the source to the field is through open canals. However, considering huge losses due to evaporation and percolation, a modern system of irrigation like pipe irrigation network (PIN) is desired. Advancement in technology has led to the progress in the PIN as they are compatible with modern irrigation facilities such as sprinkler and drip irrigation systems. In the present study, the layout of the PIN is designed and optimized in two phases. Initially, the looped network is traced out for the Bakhari distributary of the Kanhan Branch Canal, India. Minimum spanning tree (MST) network is obtained from the looped network using Prim's algorithm to calculate the nodal demands. The layout optimization of the MST is carried out using the Steiner concept to obtain the initial Steiner tree (IST). The steady-state hydraulic analysis and design are carried out for the looped and IST network. The results show that the percentage of length decreasing from the looped network to the MST network is $51.58 \%$. The IST network is the optimized network having the minimum length showing a $12.21 \%$ length reduction compared to the MST network. The total reduction in the cost of the Steiner tree is found to be $4.25 \%$ compared to the looped network. Steiner concept application to large irrigation networks can reduce the length of the network thereby minimizing the total project cost.
\end{abstract}

\section{Introduction}

Freshwater is a finite and vital resource that is essential for maintaining the life cycle on Earth. India constitutes $2.4 \%$ of the world's surface area and supports $16.7 \%$ of the world's population. It possesses only $4 \%$ of the world's water resources [1]. The estimated population of India is 1,210 million with a growth rate of $17.64 \%$ [2]. With the increase in population, the requirement for agricultural products would increase and the scarcity of water would certainly affect the production from agriculture $[3,4]$. Moreover, in the last three decades, the annual and summer precipitation showed a decreasing trend of $5 \%$, while a positive trend is observed for the temperature with a significant value of $5 \%$ [5]. This concludes that precipitation has been declining with the rapid warming in the last 30 years [6]. This indicates that the growing demands are to be satisfied with limited resources as the rainfall is also decreasing over the period. India accounts for $7.39 \%$ of total global agricultural output and as per the Economy Survey of India 2018-19, the agricultural sector contributes around $15-17 \%$ to the country's gross domestic product (GDP), which necessitates irrigation [7]. Therefore, to support the country's economy, it is necessary to save water and use it sustainably. In ancient times, the principal irrigation practice was conveying the flow of springs and streams by constructing temporary 
barriers across them and irrigating the adjoining fields by the canal system. The major drawback of the conventional canal systems is the loss of water due to percolation, evaporation, and sometimes thefts in between the reaches. Besides, the issue of land acquisition also persists. Small traditional conventional earthen channels $(200 \mathrm{~m})$ exhibit a conveyance efficiency of around $75.07 \%$, which indicates the extent of seepage loss in large irrigation networks $[8,9]$. In the case of open canals, the overall project efficiency ranges from 41 to $48 \%$, which further falls to 20 to $35 \%$ making Pipe Irrigation Network (PIN) a necessity [10]. A buried pipeline system may reduce the water demand to a significant extent with the use of a pumped irrigation system as compared to the earthen channels $[11,12]$. Considering the huge seepage and evaporation losses in irrigation water conveyance through the canal system, it is the need of the hour to shift to another efficient system as far as Indian practices are concerned. Irrigation technology made rapid strides in the $21^{\text {st }}$ century in terms of overall cost and water use efficiency. Using computer simulation, a reliable water network can be developed by forming the hydraulic models if a sufficient head is available $[13,14]$. The underground pipes in an open field give an opportunity to freely design the layout and thus making PIN a better choice in terms of both water use efficiency and overall cost. Also, it requires less execution time for undulating fields as compared to the canal distribution system. The branching (tree) water distribution networks are popular for supplying water, where the demand is very high such as irrigation and industries as they are simple in comparison to the complicated loop networks $[15,16]$. The irrigation sector is the one that requires a large amount of water in a calculated manner. An effective irrigation water supply system is required to satisfy all the demands. This is accomplished by providing an optimized pipe irrigation network.

For a given layout, an optimized PIN is the one which satisfies all the demands as well as constraints with the minimum possible cost. The cost may further be reduced if there is freedom of variation in layout as well [17]. The issue of the simultaneous layout with the design of water distribution network (WDN) optimization has been dealt with by many researchers from the last few decades. Bhave and Lam suggested a two-step approach to obtain a minimum cost WDN layout. The concept gives a minimum length layout. The lengths of the links are considered in the Steiner tree approach while the nodal discharges or hydraulic gradient level (HGL) are not given weightage for determining the optimized layout [15]. A minimum cost layout including design of WDN wherein linear programming (LP) was used to design pipe diameters and the hydraulic network solver addressed the flow through the pipes and pressures at the nodes [18]. A model of the optimized layout of WDNs with single loading was presented in which a zero-one integer model selected the pipes considering the hydraulic properties and redundancy and in the following step, design models were used to optimize the pressures and diameters resulting in an optimized layout and design of WDN [19]. Comparison of the twin genetic algorithm (GA) with binary and integer coding for the optimized layout of the branched network was carried out with dynamic programming (DP) based on time and storage requirement in both approaches [20]. An evolution program was developed in GA to optimize the looped WDN for the first time [21]. A maximum entropy-based method was developed in which the optimized cost along with reliability could be achieved for the optimized layouts [22]. A heuristic method was proposed based on reliability for the simultaneous layout and design of WDN. The network layout with the maximum number of pipes is considered initially, followed by a design float method to obtain the final least costly network [23]. An empirically derived objective function was developed for the optimal layout of the tree network using mixed integer linear programming (MILP). The data used for MILP was the location and demands of the users [24]. GIS was used in the backdrop as the classical graph theory (CGT) algorithm was used to find out the minimum length of the spanning tree [25]. A method was presented in which the pipes are removed sequentially to reach the minimum cost network to obtain the optimal layout and design of branched WDN. The design flows were obtained using Clements's method [26]. A six-looped water distribution system having seventeen links was used to demonstrate the multicriteria maximum entropy method for the optimization of link size, reliability, and network layout. The chief criterion being network, therefore, a compromise between entropy, redundancy, reliability, and network cost were observed sequentially within the population of the best solutions. As a smaller part of the network has been considered for layout and design, the efficiency of the method was improved [27]. For the optimal layout of the urban drainage network, loop-by-loop cutting algorithm based on graph theory and GA has been used [28]. A multiobjective evolutionary method was presented for the optimization of the design and layout of WDN [29]. Particle swarm optimization (PSO) technique was linked with MATLAB for irrigation WDN layout and cost optimization [30]. A fusion method of tree growing-jumping particle swarm optimization (TG-JPSO) was proposed which is a blend of layout and pipe size optimizers to achieve an optimal layout and design of WDN. A modified version of Labye's iterative discontinuous method (LIDM) was used which gives several solutions that finally converge to an optimized design [31]. Max-min ant system (MMAS) algorithm has been used to obtain the minimum cost design considering layout and pipe diameters of the network simultaneously [32]. The accuracy of various methods and their comparative studies were also carried out in the past. It was found that the ant algorithm (AA) application to the branched WDN gives better results as compared to GA [33], whereas recently developed Physarum algorithm performs better than the ant colony algorithm for optimization of branched WDNs [34]. A heuristic method based on a uniform flow network was suggested to achieve minimum variance in the pipe flows for increased reliability of the network. The system was evaluated through a variance of flow series and the obtained optimal layout network was designed using linear programming [35]. Thevenin theorem (TT) applied for electric circuits was applied for the model reduction and analysis of large WDN [36]. Recently 
developed population-based Harris hawks algorithm (HHO) was developed for the WDN optimization of the Homashahr city in Iran [37]. A novel heuristic targeted path search algorithm (TPSA) based on the determination of optimal paths followed by the flow of water in a WDN was developed for three benchmark networks. In the process of optimization, the targeted trial of decrease in pipe diameters of the network was guided by two individual subroutines, thus exploring the search space [38]. Some of the hydraulic simulation software is also coupled with these heuristic techniques to obtain the optimized design of WDN [39]. The basics of hydraulic simulation and interoperability of the water distribution network were presented and a hydraulic WDN model was prepared for scheduling and science operations of WDN with the help of SCADA data and GIS data in WaterGEMS to optimize the network effectively [40]. Steiner point concept is coupled with LP for a small 8-node example to obtain an optimized layout [41].

In the present study, a layout optimization model is developed in a stepwise manner. The approach starts with the development of a looped network for calculating the demands which are further designed and optimized using WaterGems connect. The second step consists of the conversion of the looped network into the minimum spanning tree (MST) network using Prim's algorithm. The final step is the application of the Steiner concept to the MST to obtain the Steiner tree (ST), which gives the optimized layout and design of the network. A comparison of the looped network and the ST network shows a reduction of $4.25 \%$ in the total network cost. A flowchart depicting the methodology is shown in Figure 1. The abbreviations used in this paper are tabulated in Table 1.

\section{Characterization of the Study Area}

The area selected for the present study is Bakhari distributary of the Pench irrigation project, located in Parseoni, a small town and a municipal council in Nagpur district in the state of Maharashtra, India. The study area with latitude $21^{\circ} 19^{\prime} 34.15^{\prime \prime} \mathrm{N}$ and longitude $79^{\circ} 11^{\prime} 15.55^{\prime \prime} E$ is well-connected via state and national highway. Bakhari distributary offtakes from Left Bank Canal (LBC) of Pench irrigation project having discharge capacity of 1.58 cumecs to irrigate 2057.17 Ha culturable command area (CCA). The schematic sketch of the study area is presented in Figure 2.

\section{Materials and Methods}

3.1. Looped Network. Looped networks are complex compared to the branched networks but are more reliable. On the other hand, for large irrigation networks branched networks are more economical. For the present study, the looped gravity-fed network is traced out in AutoCAD Map $3 \mathrm{D}$ along the road lines of the study area as shown in Figure 3.

The pipeline along the roads avoids the problem of land acquisition, while for layout optimization, some of the field area may be covered. The underground pipe system suffices for the utilization of the complete field area. The looped network consists of 1 source reservoir, 60 nodes, and 87 pipes to supply irrigation water to the field. It covers a total length of $59.17 \mathrm{Km}$ to irrigate 2057.17 Ha CCA with a discharge capacity of 1.578 cumecs. For the PIN, the seepage and evaporation losses are almost eliminated. However, leakage losses may be present. Considering $10 \%$ leakage losses, the gross irrigation requirement (GIR) and net irrigation requirement (NIR) for the different crops in the area are calculated as shown in Table 2.

The looped network consists of 27 polygons and the demand for each of the polygon is calculated as the percentage of the total demand (GIR) as per the area of each polygon as shown in Table 3.

The nodal demands are found out by using the Thiessen polygon tool in WaterGEMS. Pipe sizing of the PIN is carried out followed by steady-state simulation by taking a set of designed commercial diameters to optimize the total cost of the looped network as shown in Figure 3.

3.2. Minimum Spanning Tree (MST) Network. The looped PIN is converted to a branch network known as MST which is a network consisting of a set of pipes resulting in a tree connecting each node in the system. Prim's algorithm (PA) is used to obtain the MST for the study area. In the field of computer science, PA is used to find the minimum spanning tree for a connected weighted undirected graph. This means it obtains a subset of the edges forming a tree that includes every vertex, keeping into account that the total weight of all the edges in the tree is minimized. Czech mathematician Vojtèch Jarnik developed this algorithm in 1930. It was later independently developed by computer scientist Robert C. Prim in 1957 and rediscovered by Edsger Dijkstra in 1959. Therefore, it is also sometimes called the Jarnik algorithm, the DJP algorithm, or the Prim-Jarnik algorithm [42]. PA is a greedy algorithm that finds a set of the pipes forming a tree, which includes each node, where the total length of all the links in the tree is minimum. This algorithm is directly based on the MST property, which finds the global optimum solution for the minimum length. The obtained MST consists of 1 reservoir, 60 nodes, and 60 pipes with a total length of $28.65 \mathrm{Km}$ to irrigate 2057.17 Ha CCA as shown in Figure 4.

3.3. Initial Steiner Tree (IST). Further layout optimization is carried out with the concept of the Steiner tree (ST). Steiner points are the additional nodal points in an existing system to produce an optimal layout. The connecting links between different nodes and the Steiner points are considered as straight lines with link diameters as a continuous variable. The characteristics of the Steiner tree for a multinode network are as follows. (i) ST for an N-node network can have a maximum of up to N-2 Steiner points; however, it may be less when some of the given nodes also act as junction nodes. (ii) Each Steiner point is connected to three points (given nodes or other Steiner points) such that the angle between the connecting link is $120^{\circ}$. Computer algorithms and several methodologies are there to obtain the Steiner tree [43-45]. Additional Steiner points are obtained for the already existing system of nodes to obtain optimal layout using 


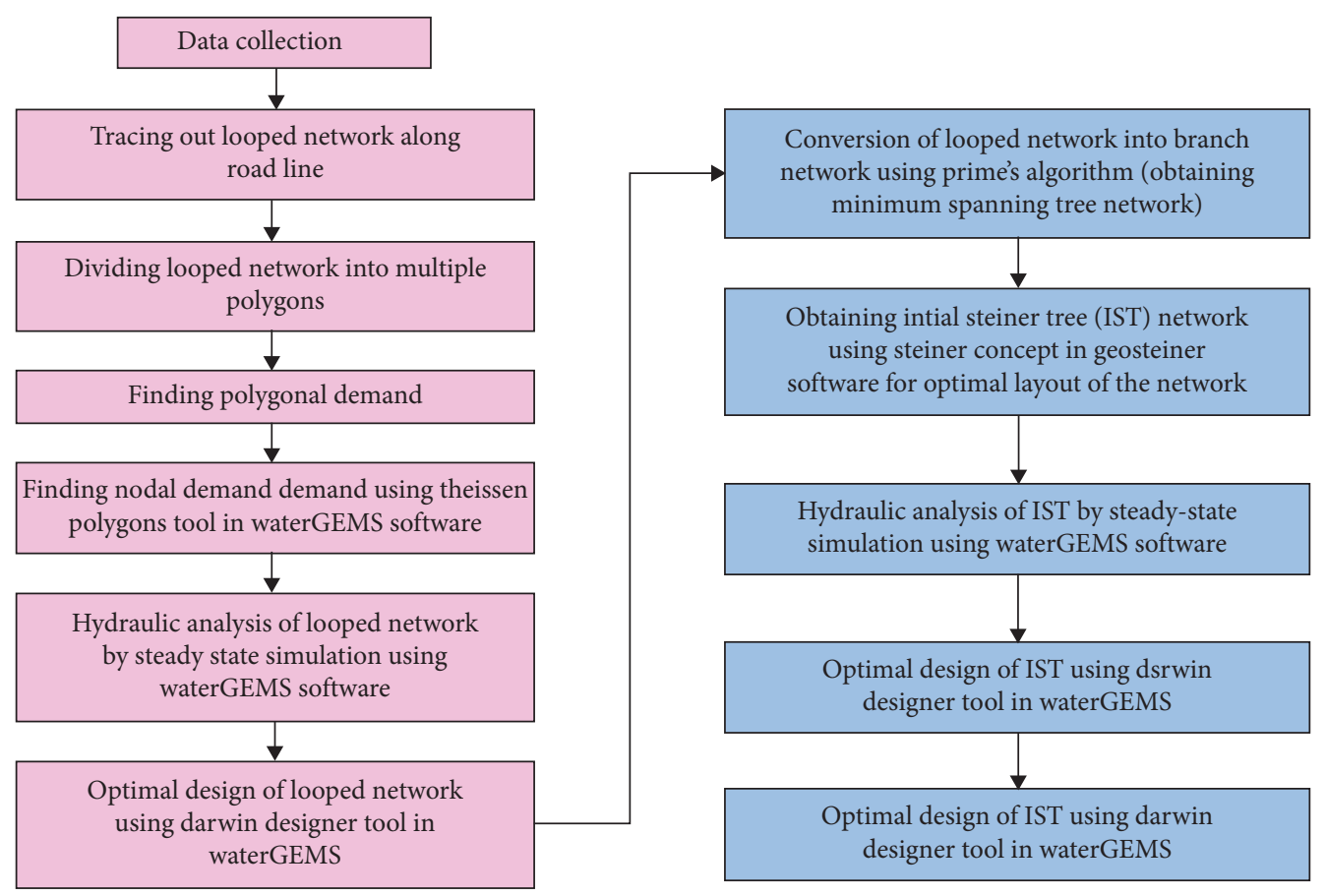

FIgURE 1: Flow chart depicting the methodology of the study.

TABLE 1: List of abbreviations.

\begin{tabular}{lc}
\hline Abbreviations & \\
\hline AA & Ant algorithm \\
CCA & Culturable command area \\
CGT & Classical graph theory \\
DP & Dynamic programming \\
GA & Genetic algorithm \\
GDP & Gross domestic product \\
GIR & Gross irrigation requirement \\
HHO & Harris Hawks algorithm \\
HGL & Hydraulic gradient level \\
IST & Initial Steiner tree \\
LBC & Left bank canal \\
LIDM & Labye's iterative discontinuous method \\
LP & Linear programming \\
MILP & Mixed integer linear programming \\
MMAS & Max-min ant system \\
MST & Minimum spanning tree \\
MST & Minimum spanning tree \\
NIR & Net irrigation requirement \\
PA & Prim's algorithm \\
PIN & Pipe irrigation network \\
PSO & Particle swarm optimization \\
ST & Steiner tree \\
TPSA & Targeted path search algorithm \\
TG-JPSO & Tree growing-jumping particle swarm optimization \\
TT & Thevenin theorem \\
WDN & Water distribution network \\
\hline
\end{tabular}

GeoSteiner software. The computation of the exact solutions to the Steiner tree problems is obtained with the help of the GeoSteiner software package which has a very fast (publicly available) program [46]. A complete written programmed code which is with a clear method to generate the Steiner tree is recorded [47]. For the present study, a new initial Steiner tree network is formulated in ArcMap which consists of 60 nodes, 21 Steiner points, 81 pipes, and 1 source reservoir as shown in Figure 5 to convey the irrigation water to all demand nodes. The total length of the network is reduced to $25.15 \mathrm{Km}$ to irrigate the same CCA. After layout optimization pipe sizing of the initial Steiner tree is carried out for the same set of designed diameters, the same network is then optimized for pipe sizing by using the Darwin designer tool in WaterGEMS, which works on GA parameters.

The optimized design study has no true optimality and only knows the best solution relative to other solutions already found during computation. In general, population size and random number seed are the common parameters to change in computing the model under consideration. The sensitivity of the existing model is tested by a random number of seeds for the model being optimized. With GA optimization having a stochastic nature, it might be beneficial to change population size up or down. Faster runs are obtained using a smaller population size, but the model is less diverse and potentially optimized results with the population being less [48]. Pressure constraints are set to maintain positive pressure at the nodes.

\section{Results and Discussion}

The initial looped network consists of 87 links and 60 nodes with a total length of $56.17 \mathrm{~km}$. The analysis of the network is carried out by considering the minimum and maximum pressure of $0.17 \mathrm{~m}$ and $20 \mathrm{~m}$, respectively. Based on these pressures, a set of designed diameters are selected in which minimum and maximum diameters are $50 \mathrm{~mm}$ and $1600 \mathrm{~mm}$, respectively. After optimizing the network, it is 


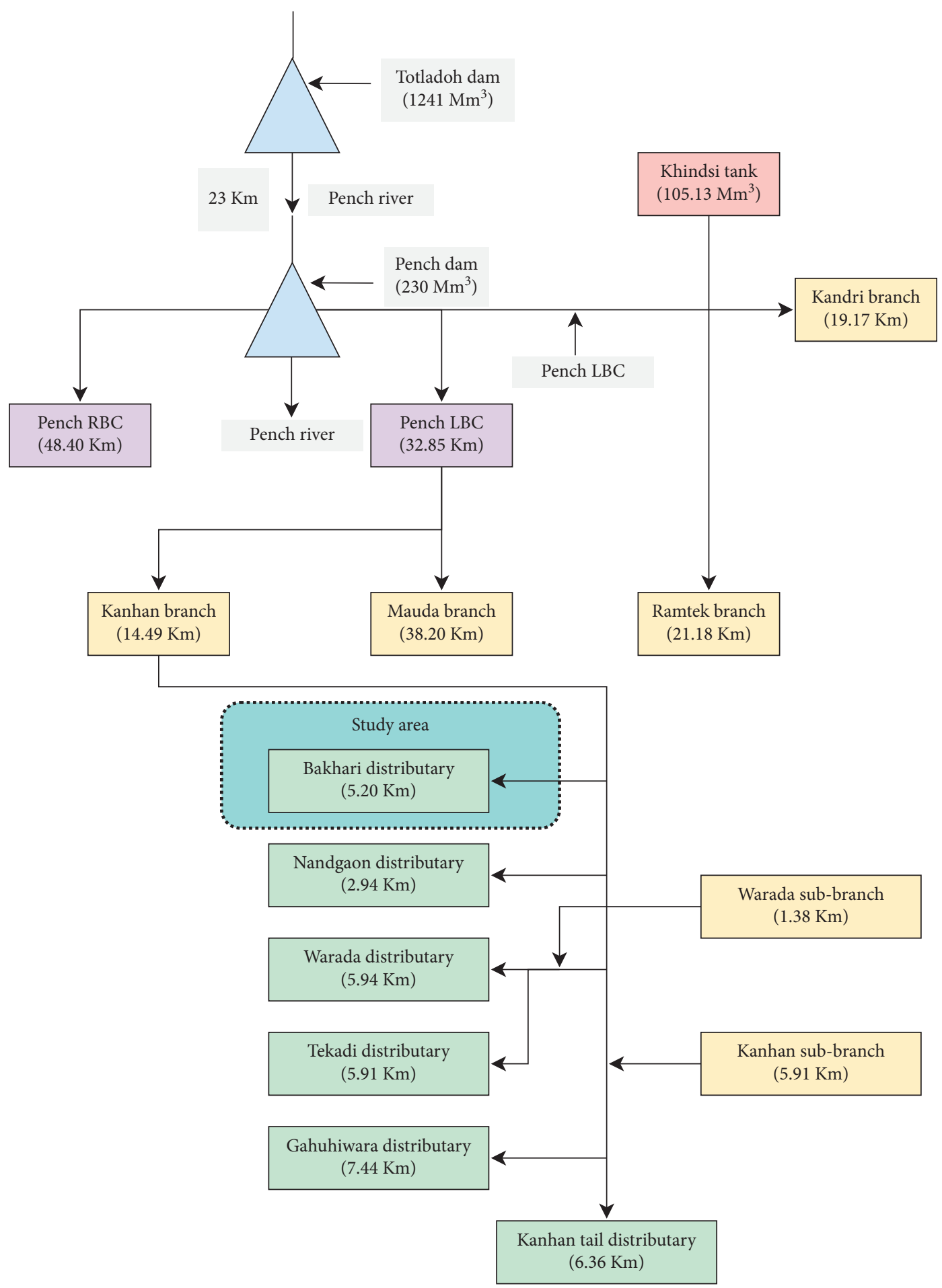

FIgURE 2: Schematic sketch of study area.

observed that out of 87 pipe diameters, 25 pipes $(3,7,10,12$, $17,18,20,27,32,33,34,36,45,50,51,55,59,68,71,72,73$, $74,79,85,87)$ diameters have a value less than the designed diameter and 2 pipes $(25,77)$ are having a diameter equal to the designed diameter as shown in Figure 6. The cost reduction is brought about as a result of the reduction in the pipe sizes of the optimized design.
Pipe sizing is carried out by considering pressure constraints in which minimum and maximum pressures are set to 0.17 and $20 \mathrm{~m}$. It is found that all the simulated pressures are positive which are well within the minimum and maximum pressure limits as shown in Figure 7. However, for only one junction (17), the pressure exceeds the upper pressure limit which is 20.95 and can be neglected. 


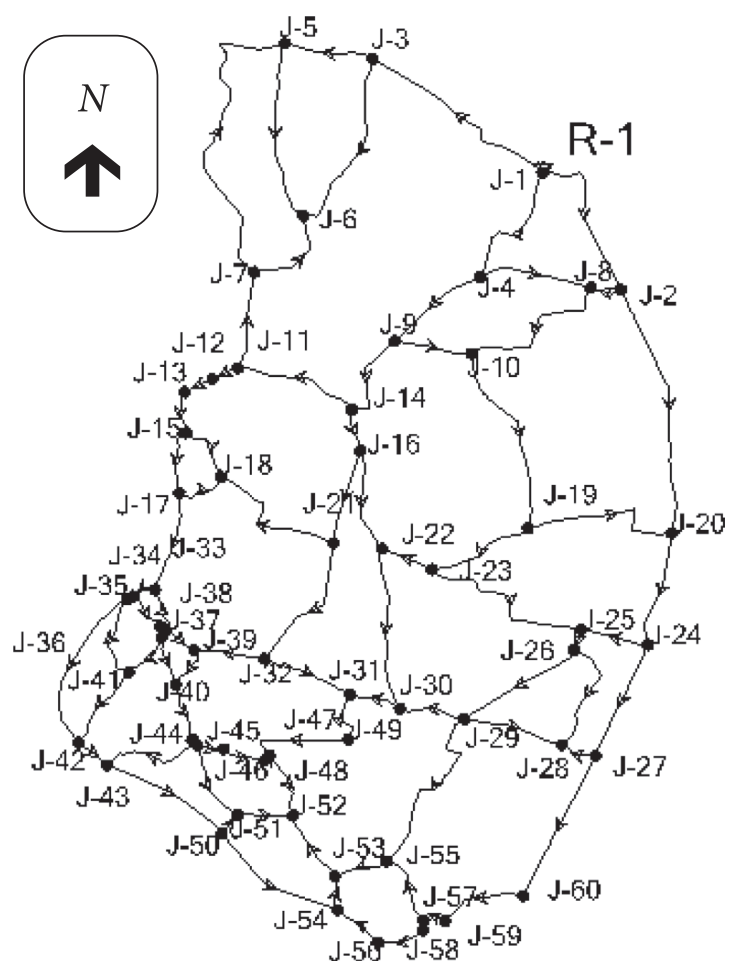

FIgURE 3: Looped network for Bakhari.

TABLe 2: NIR and GIR for $90 \%$ efficiency.

\begin{tabular}{lccccc}
\hline & \multicolumn{2}{c}{ Demand (approved) in $\mathrm{m}^{3}$} \\
Crop & $\%$ & Area $\left(\mathrm{m}^{2}\right)$ & Delta $(\mathrm{m})$ & NIR at field $\left(\mathrm{m}^{3}\right)$ & $\mathrm{GIR}^{3}$ at field $\left(\mathrm{m}^{3}\right)$ \\
\hline Sugar cane & 6 & 3464944.26 & 1.17 & 4042758.36 & 4447034.19 \\
Other perennial crops & 2 & 1154981.42 & 0.9 & 1039541.03 & 1143495.13 \\
Paddy (Kharif) & 70 & 40424349.64 & 0.31 & 12588950.96 & 13847846.06 \\
Cotton & 10 & 5774907.09 & 0.26 & 1497722.15 & 1647494.37 \\
Wheat & 12 & 6929888.51 & 0.25 & 1728175.6 & 1900993.16 \\
Total & $\mathbf{1 0 0}$ & & $\mathbf{5 7 7 4 9 0 7 0 . 9 1}$ & & $\mathbf{2 2 9 8 6 8 6 2 . 9 1}$ \\
\hline
\end{tabular}

Table 3: Areawise demand for $90 \%$ efficiency.

\begin{tabular}{lcccc}
\hline Polygon no. & Area $\left(\mathrm{m}^{2}\right)$ & $\%$ Area & GIR $\left(\mathrm{m}^{3}\right)$ & 554462.5 \\
\hline 1 & 1392956.3 & 2.41 & 472144.7 & 0.11 \\
2 & 1186152.14 & 2.05 & 302232.8 & 0.09 \\
3 & 759288.51 & 1.31 & 453007.1 & 0.06 \\
4 & 1138073.57 & 1.97 & 309142.3 & 0.09 \\
5 & 776647.09 & 1.34 & 466153.7 & 0.06 \\
6 & 1171101.22 & 2.03 & 695827.3 & 116233 \\
7 & 1748101.88 & 3.03 & 138471.6 & 0.09 \\
8 & 292008.07 & 0.51 & 104210.8 \\
9 & 347877.22 & 0.6 & 89424.64 & 0.02 \\
10 & 261804.95 & 0.45 & 177681.6 & 0.03 \\
11 & 224658.3 & 0.39 & 102850.2 & 0.02 \\
12 & 446383.18 & 0.77 & 24030.73 & 0.02 \\
13 & 258386.8 & 0.45 & 57899.28 & 0.03 \\
14 & 60371.55 & 0.1 & 15704.44 & 0.02 \\
15 & 145458.28 & 0.25 & 484818.1 & 0.01 \\
16 & 39453.71 & 0.07 & 48780.28 & 0.09 \\
18 & 1217991.22 & 2.11 & 112843.1 & 0.01 \\
19 & 122548.94 & 0.21 & 0.49 & \\
\hline
\end{tabular}


TABLE 3: Continued.

\begin{tabular}{lcccc}
\hline Polygon no. & Area $\left(\mathrm{m}^{2}\right)$ & \% Area & GIR $\left(\mathrm{m}^{3}\right)$ & Demand $\left(\mathrm{m}^{3} / \mathrm{s}\right)$ \\
\hline 20 & 1071211.4 & 1.85 & 426392.8 & 0.08 \\
21 & 1874704.24 & 3.25 & 746221 & 0.14 \\
22 & 560513.73 & 0.97 & 223111 & 0.04 \\
23 & 706984.8 & 1.22 & 312127.8 & 0.05 \\
24 & 784147.43 & 1.36 & 194264.8 & 0.06 \\
25 & 488044.43 & 0.85 & 1143923 & 0.04 \\
26 & 2873835.73 & 4.98 & 135138.7 & 0.22 \\
27 & 339504.17 & 0.59 & & 0.03 \\
\hline Total & $\mathbf{2 0 5 7 1 7 0 0 . 4 6}$ & $\mathbf{1 . 5 8}$ \\
\hline
\end{tabular}

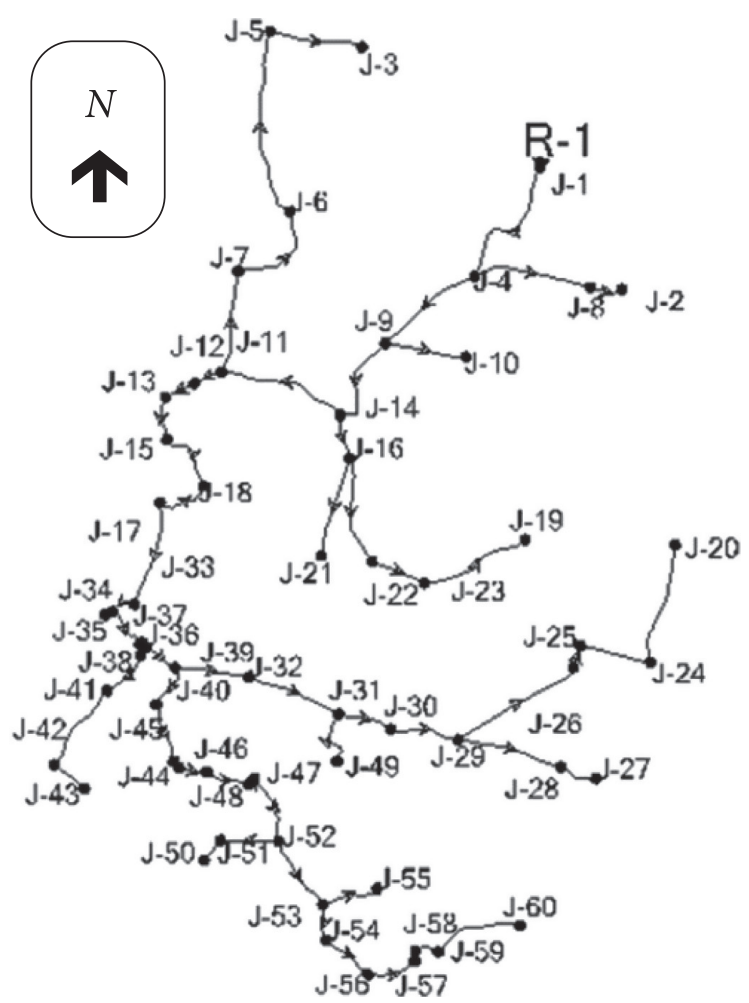

FIgURE 4: Minimum spanning tree network.

Steiner tree network consists of 81 pipes, 60 nodes, 21 Steiner points, and 1 source reservoir with a total length of $25.15 \mathrm{~km}$. Out of 81 pipes, it is observed that 23 pipes $(1,2,3,5$, $18,26,28,29,30,34,35,41,46,49,50,66,70,71,72,76,77,79$, $80)$ are having a diameter less than the designed diameter and 6 pipes $(4,10,36,40,47,81)$ have diameters equal to the designed diameter, as shown in Figure 8. The cost of the network is reduced due to the reduction in the pipe size of 23 pipes.

Steady-state simulation analysis of the Steiner tree model is carried out which results in pressure values within the permissible limit. On optimizing the network for pipe sizing, it is observed that all pressure heads are positive with simulated value ranges from 0.85 to $21.72 \mathrm{~m}$ having zero violation in pressure at each node. The obtained optimized solution is for pressure constraints of 0.65 to $23 \mathrm{~m}$. Figure 9 indicates pressure variation at each node for the initial Steiner tree. It is clear from Figure 9 that the simulated pressures are well within the considered limits.

The overall comparison between the initial looped WDS and IST is shown in Table 4 which indicates the comparison parameters as length, area, material, number of nodes and pipes, discharge capacity, and total cost of both the networks. Along with these parameters, the comparison based on hydraulic properties such as minimum and maximum 


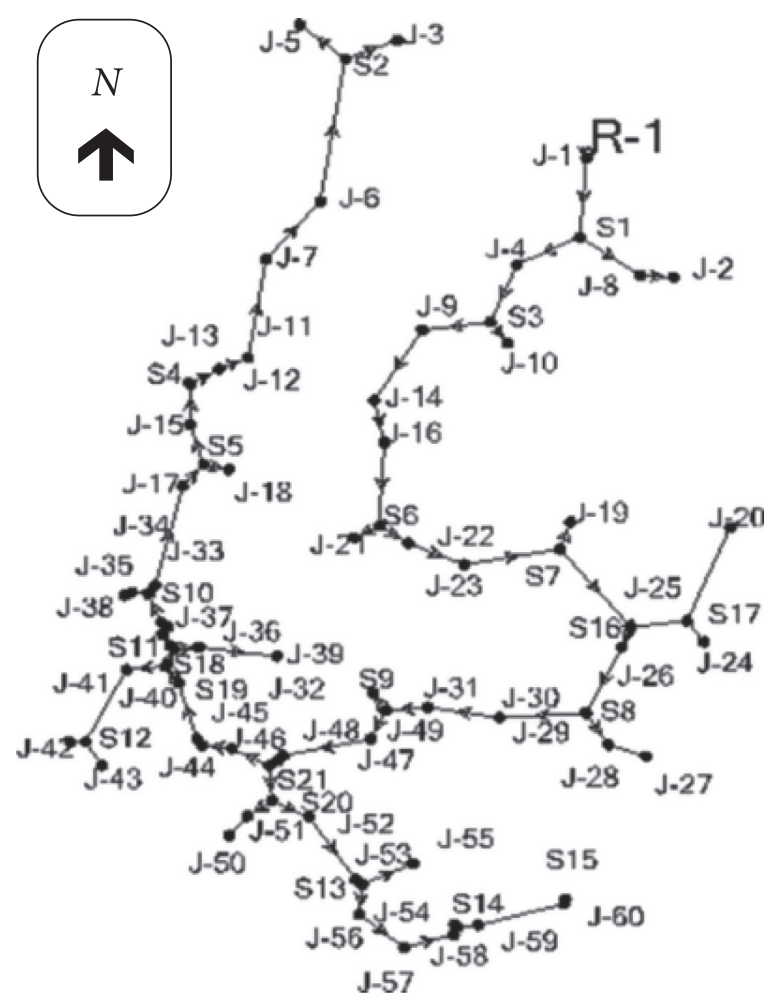

Figure 5: Steiner tree.

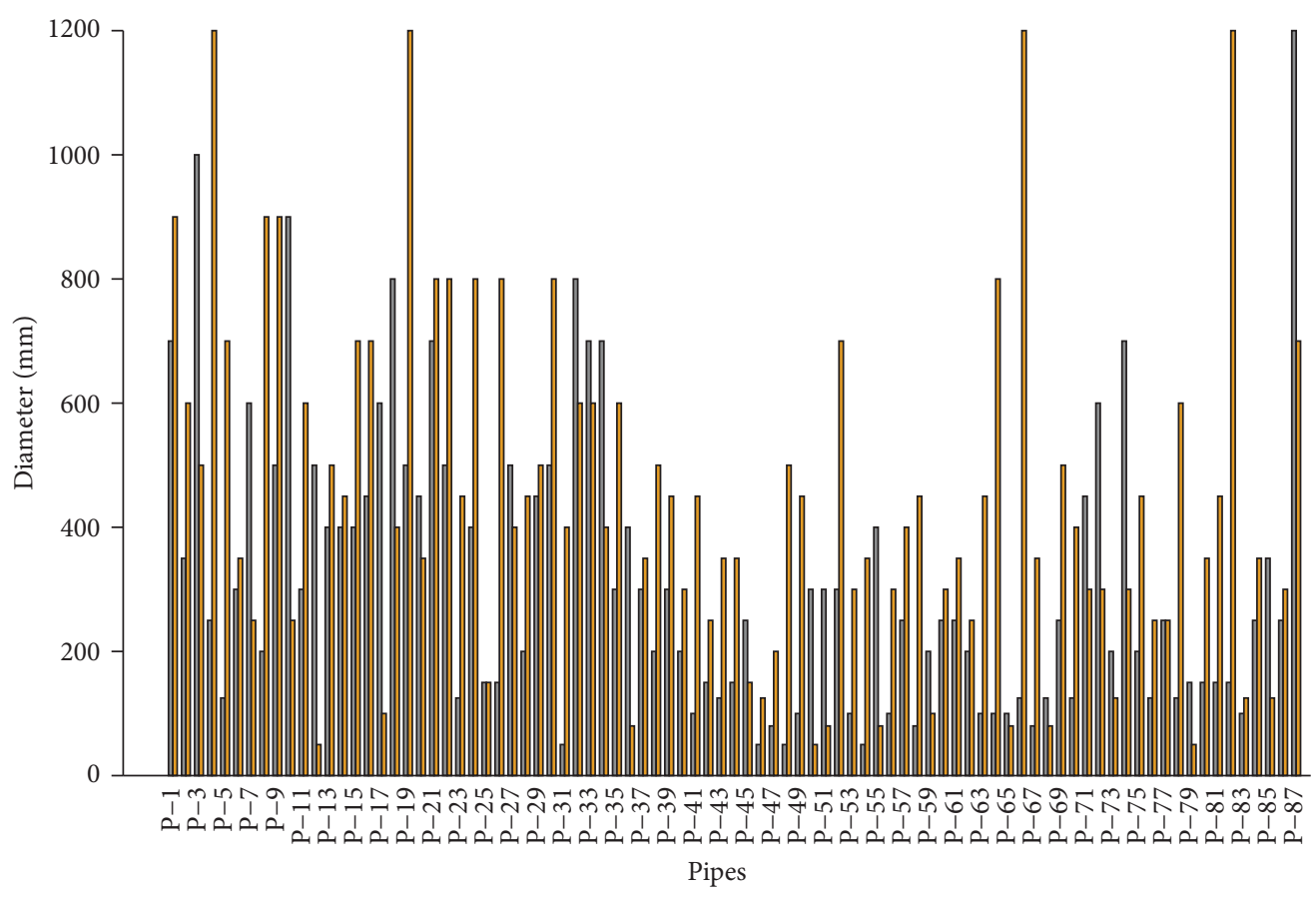

$\square$ Designed diameter $(\mathrm{mm})$

$\square$ Optimized diameter $(\mathrm{mm})$

FIGURE 6: Designed diameter versus optimized diameter of the looped network. 


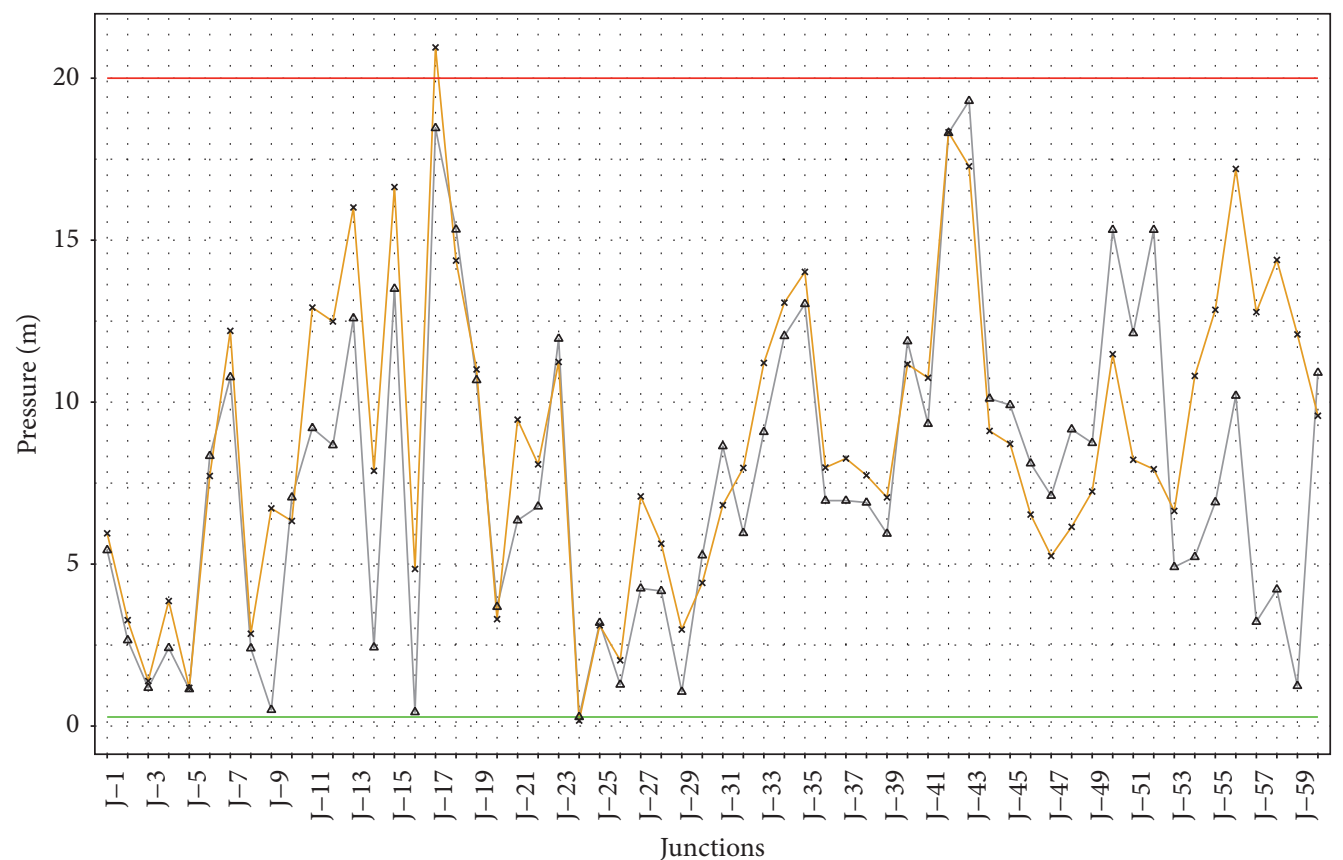

Pressure (m)

- Measured

- Minumum

Simulated

— Maximum

Figure 7: Pressure variation at each junction of looped network.

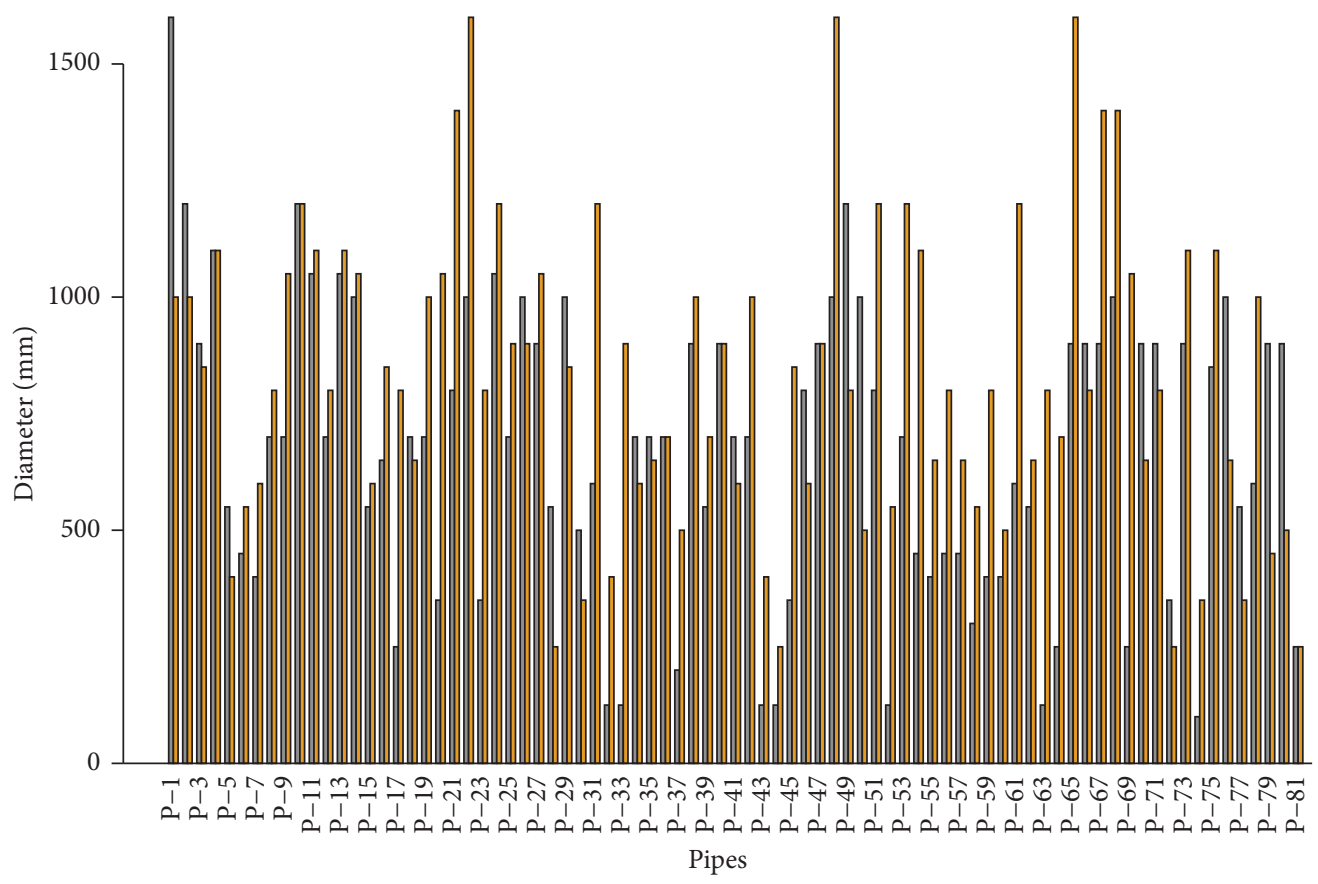

口 Designed diameter $(\mathrm{mm})$

u Optimized diameter $(\mathrm{mm})$

Figure 8: Designed diameter versus optimized diameter of initial Steiner tree network. 


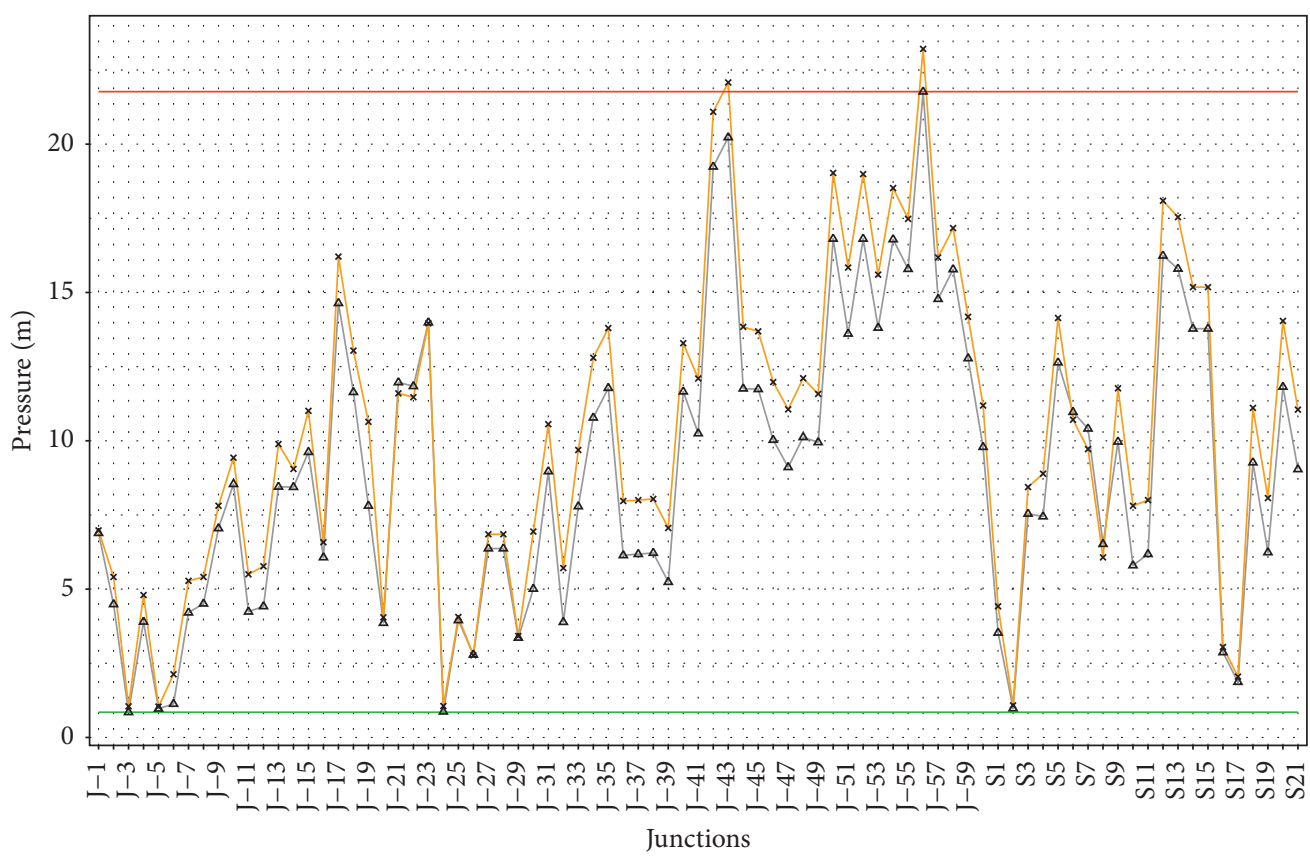

Pressure $(\mathrm{m})$

$\begin{array}{ll}\text { Measured } & \text { - Minumum } \\ \text { Simulated } & - \text { Maximum }\end{array}$

FIgURe 9: Pressure variation at each node for initial Steiner tree.

TABLE 4: Comparison between looped network and initial Steiner tree network.

\begin{tabular}{|c|c|c|c|c|}
\hline Parameter & \multicolumn{2}{|c|}{ Looped network } & \multicolumn{2}{|c|}{ IST network } \\
\hline Length $(\mathrm{km})$ & \multicolumn{2}{|c|}{59.17} & \multicolumn{2}{|c|}{25.151} \\
\hline Area $\left(\mathrm{km}^{2}\right)$ & \multicolumn{2}{|c|}{2057.17} & \multicolumn{2}{|c|}{2057.17} \\
\hline Material & \multicolumn{2}{|c|}{ PVC } & \multicolumn{2}{|c|}{ PVC } \\
\hline Source reservoir & \multicolumn{2}{|c|}{1} & \multicolumn{2}{|c|}{1} \\
\hline Node & \multicolumn{2}{|c|}{60} & \multicolumn{2}{|c|}{$81(60+21$ Steiner points $)$} \\
\hline Pipe & \multicolumn{2}{|c|}{87} & \multicolumn{2}{|c|}{81} \\
\hline Discharge capacity (cumecs) & \multicolumn{2}{|c|}{1.578} & \multicolumn{2}{|c|}{1.578} \\
\hline Total cost (rs.) & \multicolumn{2}{|c|}{25.86 crores } & \multicolumn{2}{|c|}{24.76 crores } \\
\hline Cost per km length (rs. $/ \mathrm{km})$ & \multicolumn{2}{|c|}{0.437 crores } & \multicolumn{2}{|c|}{0.984 crores } \\
\hline & Minimum & Maximum & Minimum & Maximum \\
\hline Designed diameters $(\mathrm{mm})$ & 50 & 1200 & 250 & 1600 \\
\hline Optimized diameter $(\mathrm{mm})$ & 50 & 1200 & 250 & 1600 \\
\hline Pressures (m) & 0.17 & 20 & 0.65 & 23 \\
\hline Simulated pressures $(\mathrm{m})$ & 0.28 & 19.3 & 0.85 & 21.72 \\
\hline
\end{tabular}

designed and optimized diameters and pressures and simulated pressures of both the networks is also presented.

\section{Conclusion}

As the network is buried underground, therefore the location of the nodes does not create any hindrance to on-land farming. Moreover, the increment in the number of nodes also has little effect on the functionality of the network. In the present study, initially, a looped network is analyzed and design is carried out for the total length of $59.17 \mathrm{Km}$. The total cost of looped PIN is found to be 25.86 crores, that is, 0.45 crores per $\mathrm{Km}$ length. After converting the looped network to a branch network (MST) using PA, it is observed that number of links reduced to 60 from the 87 for the same nodal demand. The length of the looped network decreases to $28.65 \mathrm{Km}$ from $59.17 \mathrm{Km}$, that is, $51.58 \%$. The final step in which the MST is converted to IST using the Steiner concept shows the reduction in network length from 28.65 to $25.151 \mathrm{Km}$, that is, $12.21 \%$ although the number of links and nodes were increased to 81 and 81 (60 already existing nodes and 21 Steiner points), respectively. The total cost of the Steiner network is 24.76 crores, that is, 0.987 crores per $\mathrm{km}$ length. The total reduction in the cost of the Steiner tree is found to be $4.25 \%$ compared to the looped network. Results highlight that though the per meter cost of the ST is higher than the initial looped network, but the two-step optimization of layout reduced the total cost of the network. Hence, 
the method proposed in the present study can be certainly utilized for the layout and pipe size optimization. As the pipes are underground, the Steiner point junctions are feasible, as no on-field problems are faced. The present work can be extended for further cost reduction, which may be possible if different pipe materials are used for different lengths of the network.

\section{Data Availability}

Data are available upon request to the corresponding author.

\section{Conflicts of Interest}

The authors declare that they have no conflicts of interest.

\section{Acknowledgments}

The data for the present study is provided by the Pench Irrigation Division, Nagpur, Maharashtra, India, under Vidarbha Irrigation Development Corporation, for which the authors extend a sincere thanks to the department.

\section{References}

[1] S. K. Jain, P. K. Agarwal, and V. P. Singh, Inter-basin Water Transfer, in Hydrology and Water Resources of India, pp. 1065-1109, Springer, Berlin, Germany, 2007.

[2] C. Chandramouli and R. General, "Census of India," Provisional Population Totals, New Delhi: Government of India, New Delhi, India, 2011.

[3] U. Surendran, C. M. Sushanth, E. J. Joseph, N. Al-Ansari, and Z. M. Yaseen, "FAO CROPWAT model-based irrigation requirements for coconut to improve crop and water productivity in Kerala, India," Sustainability (Switzerland), vol. 11, p. 18, 2019.

[4] M. Maghrebi, R. Noori, R. Bhattarai et al., "Iran's agriculture in the anthropocene," Earth's Future, vol. 8, no. 9, Article ID e2020EF001547, 2020.

[5] S. A. Salman, S. Shahid, H. A. Afan, M. S. Shiru, N. Al-Ansari, and Z. M. Yaseen, "Changes in climatic water availability and crop water demand for Iraq region," Sustainability, vol. 12, no. 8, p. 3437, 2020.

[6] K. Radhakrishnan, I. Sivaraman, S. K. Jena, S. Sarkar, and S. Adhikari, "A climate trend analysis of temperature and rainfall in India," Climate Change and Environmental Sustainability, vol. 5, no. 2, p. 146, 2017.

[7] M. Ronit and P. Divya, "The relationship between the growth of exports and growth of gross domestic product of India," International Journal of Business and Economics Research, vol. 3, no. 3, pp. 135-139, 2014.

[8] R. C. Srivastava, S. Mohanty, R. B. Singandhupe, A. K. Biswal, L. I. P. Ray, and D. Sahoo, "Studies on canal water based pressurized irrigation system in a minor irrigation command," Journal of Agricultural Engineering, vol. 43, no. 4, pp. 28-35, 2006.

[9] R. C. Srivastava et al., "Feasibility evaluation of pressurized irrigation in canal commands," Water Resources Management, vol. 24, no. 12, pp. 3017-3032, 2010.

[10] M. Satpute, P. Khandve, and M. Gulhane, "Pipe distribution nerwork for irrigation-an alternative to flow irrigation," in Proceedings of 99th Indian Science Congress Environmental
Sciences, 99th Indian Science Congress, Part II, Odisha, India, January 2012.

[11] R. v. Bentum, I. K. Smout, and X. Z. Ci, "Use of pipelines to improve surface irrigation in hebei province, China," Journal of Irrigation and Drainage Engineering, vol. 121, no. 6, pp. 405-410, 1995.

[12] I. K. Smout, "Use of low-pressure pipe systems for greater efficiency," Agricultural Water Management, vol. 40, no. 1, pp. 107-110, 1999.

[13] A. M. Michael, Irrigation: Theory and Practice, Vikas Publishing House, Chennai, TN, India, 1978.

[14] Z. M. Yaseen, P. Sihag, B. Yusuf, and A. M. S. Al-Janabi, "Modelling infiltration rates in permeable stormwater channels using soft computing techniques," Irrigation and Drainage, vol. 70, 2020.

[15] P. R. Bhave and C. F. Lam, "Optimal layout for branching distribution networks," Journal of Transportation Engineering, vol. 109, no. 4, pp. 534-547, 1983.

[16] B. Karimi, P. Mohammadi, H. Sanikhani, S. Q. Salih, and Z. M. Yaseen, "Modeling wetted areas of moisture bulb for drip irrigation systems: an enhanced empirical model and artificial neural network," Computers and Electronics in Agriculture, vol. 178, Article ID 105767, 2020.

[17] P. W. Gajghate and A. Mirajkar, "Irrigation pipe network planning at tertiary Level: an Indian case study," KSCE Journal of Civil Engineering, vol. 24, no. 1, pp. 322-335, 2019.

[18] I. C. Goulter and D. R. Morgan, "An integrated approach to the layout and design of water distribution networks," Civil Engineering Systems, vol. 2, no. 2, pp. 104-113, 1985.

[19] K. Awumah, S. K. Bhatt, and I. C. Goulter, "AN integer programming model for layout design OF water distribution networks," Engineering Optimization, vol. 15, no. 1, pp. 57-70, 1989.

[20] G. A. Walters and T. Lohbeck, “Optimal layout OF tree networks using genetic algorithms," Engineering Optimization, vol. 22, no. 1, pp. 27-48, 1993.

[21] J. W. Davidson, "Evolution program for layout geometry of rectilinear looped networks," Journal of Computing in Civil Engineering, vol. 13, no. 4, pp. 246-253, 1999.

[22] T. Tanyimboh and C. Sheahan, "A maximum entropy based approach to the layout optimization of water distribution systems," Civil Engineering and Environmental Systems, vol. 19, no. 3, pp. 223-253, 2002.

[23] M. H. Afshar, M. Akbari, and M. A. Mariño, "Simultaneous layout and size optimization of water distribution networks: engineering approach," Journal of Infrastructure Systems, vol. 11, no. 4, pp. 221-230, 2005.

[24] R. P. Lejano, "Optimizing the layout and design of branched pipeline water distribution systems," Irrigation and Drainage Systems, vol. 20, no. 1, pp. 125-137, 2006.

[25] A. G. Prats and S. G. Picó, "Layout design of irrigation networks in highly parcelled territories using geographical information system," Journal of Irrigation and Drainage Engineering, vol. 133, no. 6, pp. 573-582, 2007.

[26] P. P. Alandí, J. F. O. Álvarez, and J. M. T. Martín-Benito, "Optimization of irrigation water distribution networks, layout included," Agricultural Water Management, vol. 88, no. 1-3, pp. 110-118, 2007.

[27] T. T. Tanyimboh and Y. Setiadi, "Joint layout, pipe size and hydraulic reliability optimization of water distribution systems," Engineering Optimization, vol. 40, no. 8, pp. 729-747, 2008.

[28] A. Haghighi, "Loop-by-Loop cutting algorithm to generate layouts for urban drainage systems," Journal of Water 
Resources Planning and Management, vol. 139, no. 6, pp. 693-703, 2013.

[29] S. H. A. Saleh and T. T. Tanyimboh, "Coupled topology and pipe size optimization of water distribution systems," Water Resources Management, vol. 27, no. 14, pp. 4795-4814, 2013.

[30] S. Bao-Feng and M.-Y. Du Xue, "Optimization of tree pipe networks layout and size, using particle swarm optimization," WSEAS Transactions on Computers, vol. 13, pp. 219-230, 2014

[31] M. J. Monem and B. S. Kashkooli, "New discrete particle swarm optimization applied to the design of pressurized irrigation networks," Journal of Irrigation and Drainage Engineering, vol. 143, no. 1, Article ID 04016071, 2017.

[32] M. Masoumi, B. S. Kashkooli, M. J. Monem, and H. Montaseri, "Multi- objective optimal design of on- demand pressurized irrigation networks," Water Resources Management, vol. 30, no. 14, pp. 5051-5063, 2016.

[33] M. H. Afshar and M. A. Mariño, "Application of an ant algorithm for layout optimization of tree networks," Engineering Optimization, vol. 38, no. 3, pp. 353-369, 2006.

[34] E. Koritsas, E. Sidiropoulos, and C. Evangelides, "Optimization of branched water distribution systems by means of a physarum-inspired algorithm," Proceedings, vol. 2, no. 11, p. 598, 2018.

[35] R. Gupta and S. Rathi, "Joint consideration of layout and pipe sizes for water distribution network design with reliability," Procedia Engineering, vol. 186, pp. 357-363, 2017.

[36] R. Balireddy, A. Chakravorty, S. N. Kuiry, and S. M. Bhallamudi, "Application of Thevenin Theorem for model reduction and analysis of large water distribution networks," World Environmental and Water Resources Congress 2020, American Society of Civil Engineers, Virginia, USA, 2020.

[37] S. Khalifeh, S. Akbarifard, V. Khalifeh, and E. Zallaghi, "Optimization of water distribution of network systems using the Harris Hawks optimization algorithm (Case study: Homashahr city)," MethodsX, vol. 7, p. 100948, 2020.

[38] A. Manolis, E. Sidiropoulos, and C. Evangelides, "Targeted path search algorithm for optimization of water distribution networks," Urban Water Journal, pp.1-13, 2021, in Press.

[39] D. F. Ahmed and M. Y. Nawaf, "Design of multivariable control system of a distillation tower via simulation using MATLAB/simulink," Tikrit Journal of Engineering Sciences, vol. 26 , no. 3, pp. 43-50, 2019.

[40] B. Jiang, F. Zhang, J. Gao, and H. Zhao, "Building a water distribution network hydraulic model by using WaterGEMS," ICPTT 2012, American Society of Civil Engineers, Virginia, USA, 2012.

[41] R. Gupta, V. Upadhyaya, and V. K. Sudhan, "Optimal layout and sizing of pipe distribution network considering steiner points," World Environmental and Water Resources Congress 2019, American Society of Civil Engineers, Virginia, USA, 2019.

[42] E. O. Frimpong, Minimum Connection of Pipes for Water Distribution Network in Agric Nsima, Springer, Berlin, Germany, 2012.

[43] F. C. Harris, "Steiner minimal trees: their computational past, present, and future," Journal of Combinatorial Mathematics and Combinatorial Computing, vol. 30, pp. 195-220, 1999.

[44] W. M. Boyce, "An improved program for the full steiner tree problem," ACM Transactions on Mathematical Software, vol. 3, no. 4, pp. 359-385, 1977.
[45] P. Winter and M. Zachariasen, "Euclidean Steiner minimum trees: an improved exact algorithm," Networks, vol. 30, no. 3, pp. 149-166, 1997.

[46] D. Juhl, D. M. Warme, P. Winter, and M. Zachariasen, "The GeoSteiner software package for computing Steiner trees in the plane: an updated computational study," Mathematical Programming Computation, vol. 10, no. 4, pp. 487-532, 2018.

[47] M. Z. do Nascimento, V. R. Batista, and W. R. Coimbra, "An interactive programme for weighted Steiner trees," Journal of Physics: Conference Series, vol. 574, p. 12073, 2015.

[48] T. M. Walski, D. V Chase, and D. A. Savic, Water Distribution Modeling, Springer, Berlin, Germany, 2001. 